Applicants should preferably have a record of experience in the Arctic or Subarctic and proven administrative ability.

Salary and rank will be commensurate with the appointee's qualifications, and may be made at the rank of professor. Applications, together with references and supporting documents, including educational, professional and personal dossiers, should be submitted without delay to: Dr. C. S. Brant, Chairman, Board of Directors, Boreal Institute, c/o Department of Anthropology, University of Alberta, Edmonton, Alberta, Canada.

\section{Department of Northern Affairs and National Resources: Announcement}

A university graduate, fluent in the Russian language and with above-average ability to communicate in writing, is required to advise on the progress of northern developments in countries other than Canada through a review of technical publications dealing with northern scientific research, mining, transportation, development, and administration of indigenous peoples.

\section{Reviews}

ANTARCTIC BIBLIOGRAPHY. George A. Doumani, ed. Prepared at the Library of Congress and sponsored by the Office of Antarctic Programs, National Science Foundation. Washington: U.S. Government Printing Office, $1965.8 \times 101 / 2$ inches. vi +506 pages. $\$ 4.25$ U.S.

This first volume of a new bibliographical series, which promises to be
Details and application forms may be obtained from the Civil Service Commission of Canada, Ottawa 4. Quote 66-110-05.

\section{Opportunity for Photographers}

A Canadian Centennial Exhibition of Colour Photography is being organized by The Colour Photographic Association of Canada Inc. under the sponsorship of the Centennial Committee, Ottawa. Colour slides in $2 \times 2$ in. or $2-3 / 4$ in. $x 2-3 / 4$ in. mounts or colour prints on $16 \times 20$ in. mounts may be entered up to 31 October 1966 in competition for valuable awards. Also an exhibition slide show will be made up from the entries to be available for wide distribution.

Any Canadian subject photographed by a Canadian is eligible but the request is made here especially for pictures of Canada's North: the people and their doings; industry and commerce; buildings and structures; landscapes; flowers and animals.

For further information and entry forms write to: Focus on Canada, P.O. Box 545, Hamilton, Ontario, Canada.

a major contribution to polar bibliography, contains citations and abstracts of 2,000 books and articles about the antarctic regions published between 1962 and 1964. It was prepared in the Library of Congress by the Cold Regions Bibliography Section of the Science and Technology Division. It was financed by the Office of Antarctic Programs, a division of the National 
Science Foundation. In explanation of the bibliography, Mr. T. O. Jones, head of the Office of Antarctic Programs, observes:

The establishment of the U.S. Antarctic Research Program and the assignment to the National Science Foundation of the responsibility to serve as the clearinghouse for Antarctic information, conferred upon the Foundation a clear obligation to bring the Antarctic literature under bibliographic control and make it available to the Antarctic community in the United States.

We have been hearing, for years past, a great deal about international co-operation in Antarctica. One might have thought that such an international spirit would be implicit in the concept of this volume. It is, however, a distinctively American accomplishment and it owes little or nothing to cooperation with institutions of other nations interested in Antarctica, which are, of course, equally interested in bibliographical control of the literature.

In a description of the publications cited, the editor of the volume points out, "... these statistics represent the numerical proportions of the materials included in this volume, and not an analysis of the world's output of Antarctic literature." And well he may say so, because nearly half of the 2,000 entries ( 876 or $43.8 \%$ ) are from the United States. There are some 350 entries from Great Britain, about 290 from the Soviet Union, and about 105 from France - a small fraction of the antarctic literature produced by those countries. It appears, therefore, that, in this volume at least, "the Antarctic community in the United States" is, to a considerable extent, having its own literature organized for itself.

In preparing this volume, the bibliographers have had, evidently, to work within limitations. Admiration for the consistency, completeness, and accuracy of the citations and their abstracts gives way to wonder at the curious arrangement of the citations and to vexation with the index. In explanation of these clumsy features, it should be said that the primary task of the bibliographer is not the preparation of a volume but the preparation of $3 \times 5$ in. cards bearing citations and abstracts of the literature as it appears. These cards are sent with the least possible delay to the Office of Antarctic Programs and (free) to other interested institutions. The cards are, therefore, numbered consecutively as they are prepared. For volume publication the cards were sorted into 13 categories by arithmetical rather than alphabetical progression. To these many categories, there is not one index, but four: authors, subjects, geographical names, and, of all things, grantees. (This last is a roster of institutions and organizations whose work, represented in the bibliography, was supported by the National Science Foundation. How this roster serves scholarship is not clear: it looks like little more than self-congratulation.) The four indexes refer back to a citation by a letter that indicates the category and by the number it was assigned in its preparation. One longs for a simple alphabetical listing of citations and a comprehensive author-and-short-title index, even should these amenities mean some delay in volume publication and an increase in its cost.

Antarctic bibliography, despite the limited scope and inconvenient arrangement of its first volume, will be welcomed by many more persons than just those constituting the Antarctic community in the United States. Perhaps the reception of this first volume will encourage the sponsor to enlarge the scope of future volumes and to deal not only with current but also with historical literature.

Alan Cooke 